\title{
Prophylactic Ketamine Attenuates Learned Fear
}

\author{
Josephine C McGowan ${ }^{1,2}$, Christina T LaGamma ${ }^{2,3}$, Sean C Lim ${ }^{3}$, Melina Tsitsiklis', Yuval Neria ${ }^{4,5}$, \\ Rebecca A Brachman ${ }^{4}$ and Christine A Denny, ${ }^{*, 4}$
}

'Doctoral Program in Neurobiology and Behavior, Columbia University, New York, NY, USA; ${ }^{2}$ Barnard College of Columbia University, New York, NY, USA; ${ }^{3}$ Division of Integrative Neuroscience, Research Foundation for Mental Hygiene, Inc. (RFMH)/New York State Psychiatric Institute (NYSPI), New York, NY, USA; ${ }^{4}$ Department of Psychiatry, Columbia University, NYSPI Kolb Research Annex, New York, NY, USA; ${ }^{5}$ Department of Epidemiology, Columbia University, New York, NY, USA

\begin{abstract}
Ketamine has been reported to be an efficacious antidepressant for major depressive disorder and posttraumatic stress disorder. Most recently, ketamine has also been shown to be prophylactic against stress-induced depressive-like behavior in mice. It remains unknown, however, when ketamine should be administered relative to a stressor in order to maximize its antidepressant and/or prophylactic effects. Moreover, it is unknown whether ketamine can be prophylactic against subsequent stressors. We systematically administered ketamine at different time points relative to a fear experience, in order to determine when ketamine is most effective at reducing fear expression or preventing fear reactivation. Using a contextual fear conditioning (CFC) paradigm, mice were administered a single dose of saline or ketamine $(30 \mathrm{mg} / \mathrm{kg})$ at varying time points before or after CFC. Mice administered prophylactic ketamine I week, but not I month or I h before CFC, exhibited reduced freezing behavior when compared with mice administered saline. In contrast, ketamine administration following CFC or during extinction did not alter subsequent fear expression. However, ketamine administered before reinstatement increased the number of rearing bouts in an open field, possibly suggesting an increase in attentiveness. These data indicate that ketamine can buffer a fear response when given a week before as prophylactic, but not when given immediately before or after a stress-inducing episode. Thus, ketamine may be most useful in the clinic if administered in a prophylactic manner I week before a stressor, in order to protect against heightened fear responses to aversive stimuli.

Neuropsychopharmacology (2017) 42, I577-1589; doi:I0.1038/npp.2017.19; published online 22 March 2017
\end{abstract}

\section{INTRODUCTION}

Posttraumatic stress disorder (PTSD) is an illness characterized by persistent, vivid re-experiencing of a traumatic event, hyperarousal, and avoidance of stimuli associated with the trauma (Charney et al, 1993). It has been estimated that $7-8 \%$ of the US population will experience PTSD at some point in their lives and about eight million adults suffer from the disorder each year (Kessler et al, 1995; Kessler et al, 2005).

Currently, clinicians rely on several methods to reduce the symptomology of PTSD including pharmacology, psychotherapy, or a combination of both methods. A first-line approach to the pharmacological treatment of PTSD involves the use of selective serotonin reuptake inhibitors (SSRIs) (Pradhan et al, 2016). However, Stein et al (2006) found that only $59 \%$ of individuals receiving SSRI treatment for PTSD responded to treatment after 14 weeks. Other pharmacotherapies include benzodiazepines and anti-adrenergic agents, but these drugs are largely ineffective (Henry et al, 2007).

\footnotetext{
*Correspondence: Dr CA Denny, Department of Psychiatry, Columbia University, NYSPI Kolb Research Annex, Room 777, I05I Riverside Drive, Unit 87, New York, NY 10032, USA, Tel: +I 646774 7I00, Fax: + 646774 7102, E-mail: cad2125@cumc.columbia.edu Received 5 September 2016; revised 13 January 2017; accepted 18 January 2017; accepted article preview online 27 January 2017
}

These studies suggest that there is a critical need for improvements in drug therapy for PTSD. Alternatively, psychiatrists use cognitive behavioral therapy (CBT), which involves fear extinction through safe exposure to traumarelated cues (Golub et al, 2009). Other methods of psychotherapy include group therapy (Lubin et al, 1998), eye movement desensitization and reprocessing (Shapiro, 1989), and mindfulness-based cognitive training techniques (Hofmann et al, 2010). However, given the lack of empirical evidence and clinical utility of psychotherapy for trauma victims, consistent therapies have not been established (Steenkamp et al, 2015).

In light of the paucity of treatments for PTSD, researchers are pursuing potential strategies to prevent the onset of the PTSD and other psychiatric illnesses (Bernardini et al, 2016; Horn et al, 2016; Skeffington et al, 2016; Wald et al, 2016). Part of this work stems from an interest in methods to enhance stress resilience to prevent the onset of mental illness (Horn et al, 2016). A focus on preventative approaches can alleviate years of psychological and financial burden in victims of PTSD and their loved ones. Ketamine, an antagonist of the glutamate $N$-methyl-D-aspartate (NMDA) receptor and an activator of AMPA receptors, confers several properties that highlight its candidacy as a preventative treatment. Ketamine has emerged as a rapid-acting antidepressant for treatment-resistant major 
depressive disorder patients, as it takes effect within $2 \mathrm{~h}$ of administration (Zarate et al, 2006) and has sustained effects for approximately 1-2 weeks (Berman et al, 2000). In contrast to previously mentioned SSRIs, ketamine has the benefit of being administered as a single dose (Zarate et al, 2006; Murrough et al, 2013). Importantly, we recently found that ketamine administered as a prophylactic protects against the onset of stress-induced depressive-like behavior in three different mouse models of stress (Brachman et al, 2016, reviewed in Price, 2016). This work was replicated by an independent group that found similar effects of ketamine in rats (Amat et al, 2016).

In addition to its antidepressant properties, ketamine has been found to be efficacious in the treatment of chronic PTSD (Feder et al, 2014). Feder et al (2014) found that intravenous infusion of ketamine hydrochloride $(0.5 \mathrm{mg} / \mathrm{kg})$ was associated with significant and rapid reduction in PTSD symptom severity when compared with midazolam. Moreover, an initial study showed that the prevalence of PTSD was decreased in military patients that received ketamine during an operation for burns when compared with patients not receiving ketamine (McGhee et al, 2008). However, a follow-up study by the same authors failed to replicate their initial findings (McGhee et al, 2014). These studies bring into question how the dosing and timing of ketamine alters its efficacy as a prophylactic or treatment for PTSD. When ketamine should be administered, in order to maximize its protective effects, remains unknown.

In this study, in order to better understand when ketamine should be given relative to a stressful episode, we systematically administered ketamine at various time points during a CFC extinction paradigm. We hypothesized that at certain time points ketamine would be prophylactic against fear expression, whereas at other time points ketamine would be ineffective or increase fear expression. Mice administered prophylactic ketamine 1 week, but not 1 month, before CFC exhibited reduced freezing behavior when compared with mice administered saline. In contrast, ketamine administration following CFC or before extinction did not alter subsequent fear expression. Interestingly, ketamine administration following extinction, but before reinstatement, increased rearing in the open field (OF), which may reflect increased attentiveness. These data indicate that ketamine can buffer a fear response when given as a prophylactic.

\section{MATERIALS AND METHODS}

\section{Mice}

129S6/SvEvTac mice were purchased from Taconic (Hudson, $\mathrm{NY}$ ) at 8 weeks of age. Mice were housed four to five per cage in a $12 \mathrm{~h}(06: 00-18: 00 \mathrm{~h})$ light-dark colony room at $22^{\circ} \mathrm{C}$. Food and water were provided ad libitum. Behavioral testing was performed during the light phase. All experiments were approved by the Institutional Animal Care and Use Committee at Columbia University and the New York State Psychiatric Institute.

\section{Drugs}

A single injection of saline $(0.9 \% \mathrm{NaCl})$ or ketamine $(30 \mathrm{mg} / \mathrm{kg}$ ) (Ketaset III, Ketamine $\mathrm{HCl}$ injection, Fort Dodge
Animal Health, Fort Dodge, IA) was administered once during the course of each experiment. Ketamine was prepared in physiological saline and all injections were administered intraperitoneally (i.p.) in volumes of $0.1 \mathrm{cc} /$ $10 \mathrm{mg}$ body weight.

\section{Contextual Fear Conditioning}

A three-shock contextual fear conditioning (CFC) paradigm was administered as previously described (Drew et al, 2010; Denny et al, 2014). Mice were placed in the conditioning chamber and received 3 shocks 180,240 , and $300 \mathrm{~s}$ later $(2 \mathrm{~s}$, $0.75 \mathrm{~mA}$ ) and were removed $15 \mathrm{~s}$ following the last shock. Supplementary Table S1 lists all contextual information. All sessions were scored for freezing using FreezeView2 (http:// actimetrics.com/downloads/freezeframe/).

\section{Extinction (E)}

Initially, two extinction protocols based off of Trouche et al (2013) and Sananbenesi et al (2007) were piloted, in order to determine the best conditions for assessing the effectiveness of ketamine (Supplementary Figure S1). The extinction procedure chosen was the most consistent and robust, and was based on the protocol from Trouche et al (2013). Extinction began 4 days after the initial three-shock CFC procedure, or 4 days after the reinstatement procedure. Each group of mice was subjected to two extinction trials per day. Each extinction trial lasted $30 \mathrm{~min}$, with an intertrial interval of at least $2 \mathrm{~h}$. For each extinction trial, mice were placed in the same box used for CFC without receiving foot shocks. All trials were scored for freezing. The dashed line for each figure represents an $20 \%$ freezing level and reference point for extinction of fear. The freezing presented throughout the text represents averaged freezing behavior for the first $3 \mathrm{~min}$ of each extinction trial.

\section{Reinstatement (R)}

Reinstatement took place in the same Coulbourn fearconditioning box, but with altered cues. A one-shock CFC paradigm was administered as previously described (Drew et al, 2010; Denny et al, 2012, 2014), with the exception of two experiments in which the mice were administered three shocks.

\section{Forced Swim Test}

The forced swim test (FST) was administered as previously described (Richardson-Jones et al, 2010; Brachman et al, 2016).

\section{Open Field}

OF protocol was administered as previously described (Richardson-Jones et al, 2010).

\section{Statistical Analysis}

All data were analyzed using StatView 5.0 software (SAS Institute, Cary, NC) or Prism 5.0a. Alpha was set to 0.05 for all analyses. In general, the effect of Drug or Context was 
a
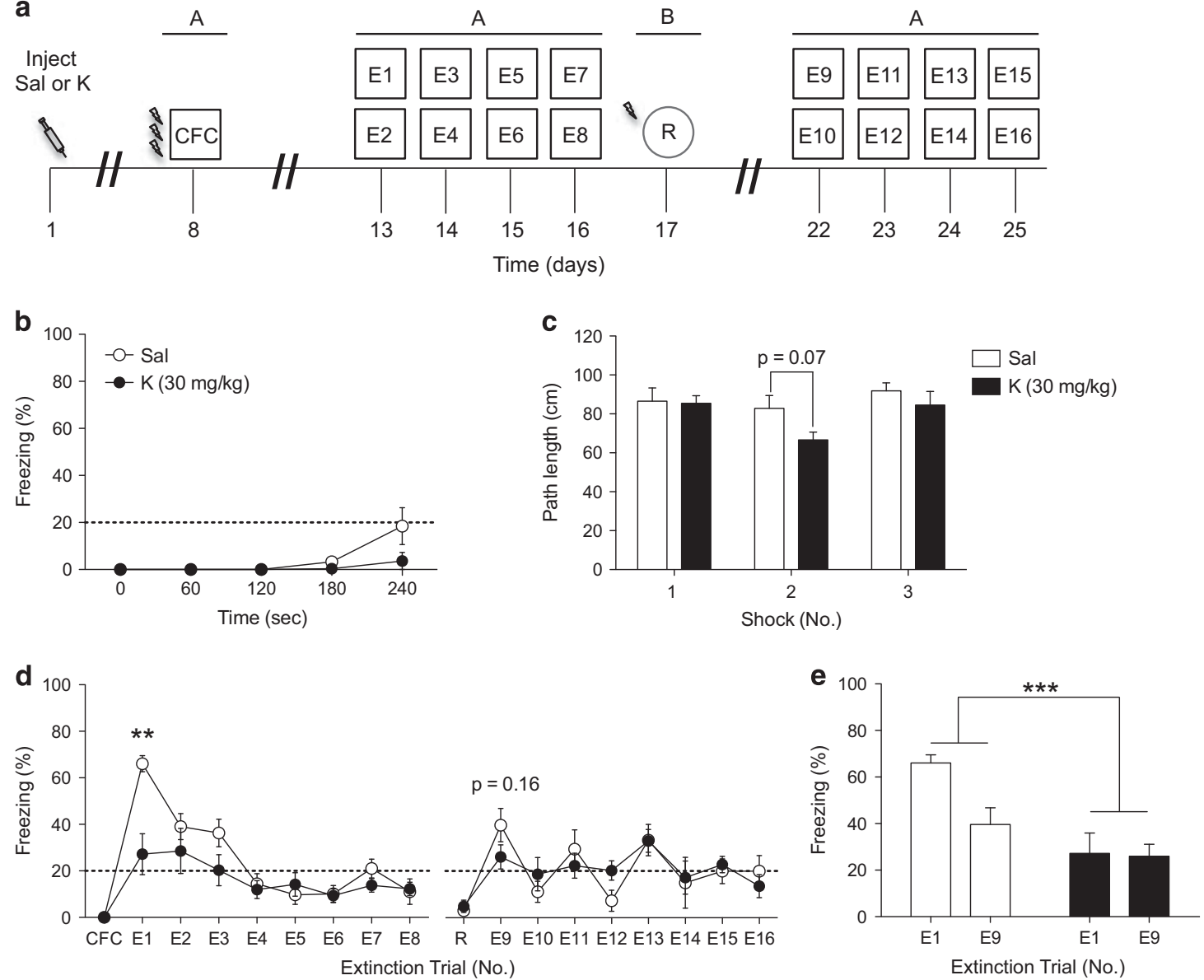

Figure I Prophylactic ketamine administration I week before CFC results in a decreased fear response. (a) Experimental design. (b) During CFC training, mice injected with saline or ketamine displayed similar levels of freezing. (c) Both groups of mice traveled comparably during each of the 3 shock presentations. (d) During the first extinction exposure, prophylactic ketamine-injected mice expressed significantly less freezing behavior when compared with saline-injected mice. Both groups of mice expressed similar levels of freezing behavior during subsequent extinction trials, reinstatement, and secondary extinction trials. (e) Ketamine-injected mice exhibited significantly less fear during extinction than saline-injected mice ( $n=5$ mice per group). Error bars represent \pm SEM. *** $<0.0$ I, and **** $<0.00$ I. CFC, contextual fear conditioning; E, extinction; K, ketamine; R, reinstatement; Sal, saline.

analyzed using an analysis of variance (ANOVA), using repeated measures where appropriate. Significant ANOVAs were followed up with Fisher's protected least significant difference post-hoc analysis or unpaired $t$-tests where appropriate. All statistical tests and $p$-values are listed in Supplementary Table S2.

\section{RESULTS}

\section{An Injection of Ketamine 1 Week Before CFC Decreases Fear Expression}

First, to determine whether our previously reported prophylactic effect of ketamine extended to $\mathrm{CFC}$, mice were administered a single injection of saline or ketamine $(30 \mathrm{mg} / \mathrm{kg})$ (Figure 1a). One week later, mice were trained using a three-shock CFC protocol. Both groups of mice exhibited comparable levels of freezing during the threeshock CFC training (Figure 1b). Moreover, both groups of mice traveled comparably during each of the three-shock presentations (Figure 1c). Extinction training began 4 days later after CFC. During the first extinction exposure, mice injected with prophylactic ketamine expressed significantly less freezing behavior when compared with mice injected with saline (Figure 1d). Both groups of mice expressed similar levels of freezing behavior during subsequent extinction trials, reinstatement, and secondary extinction trials. When the first trial of extinction and the first trial of re-extinction (E1 and E9) were compared between the two groups, ketamine-injected mice showed significantly decreased levels of fear as compared with saline-injected mice (Figure 1e). These data indicate that ketamine is efficacious in buffering fear expression when administered as a prophylactic 1 week before CFC.

\section{An Injection of Ketamine 1 Month Before CFC Does Not Alter Fear Expression}

In order to determine whether administering ketamine at additional points before a fear-inducing stimuli might be beneficial, we varied the interval from 1 week to 1 month before CFC (Figure 2a). Prophylactic ketamine administration 1 month before CFC did not result in a decreased fear response during CFC training (Figure 2c), did not alter the 
a

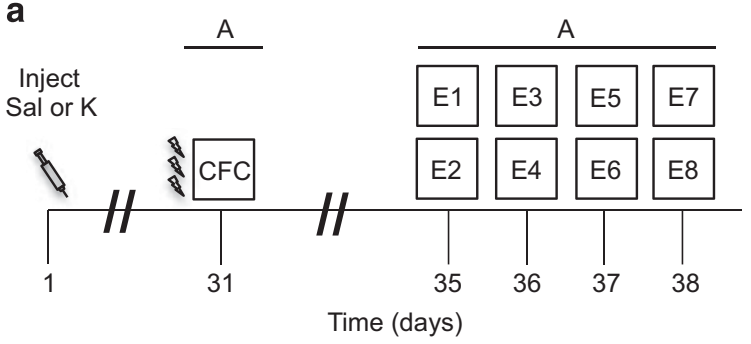

b

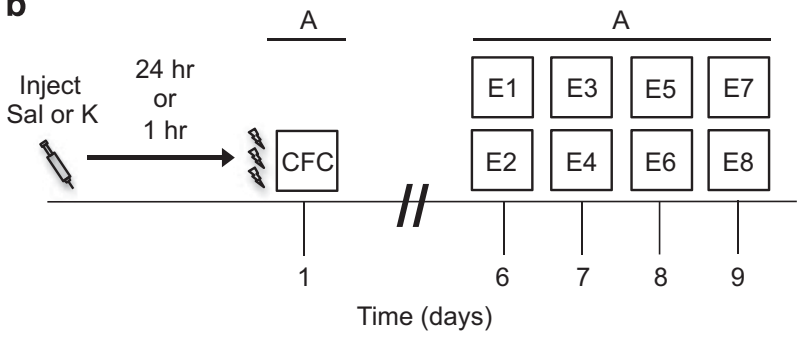

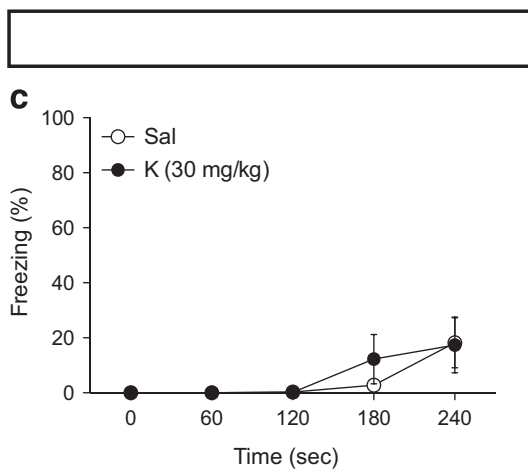

1 month prior to CFC
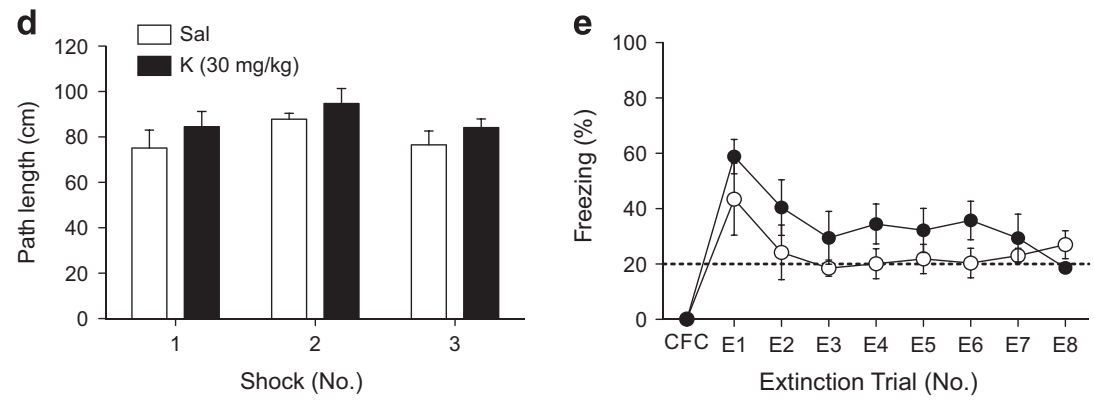

24 hours prior to CFC
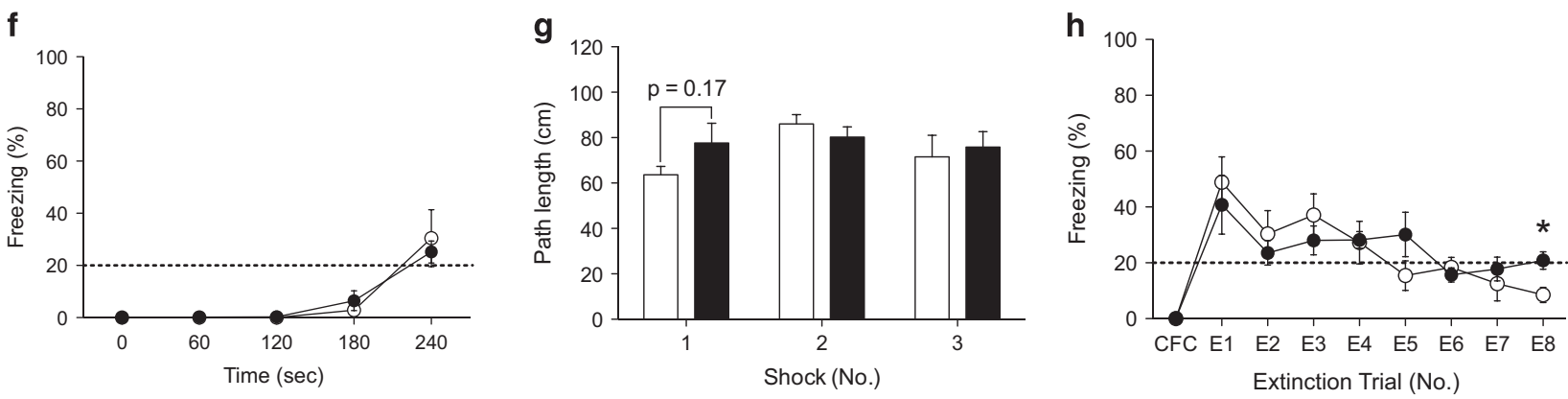

1 hour prior to CFC
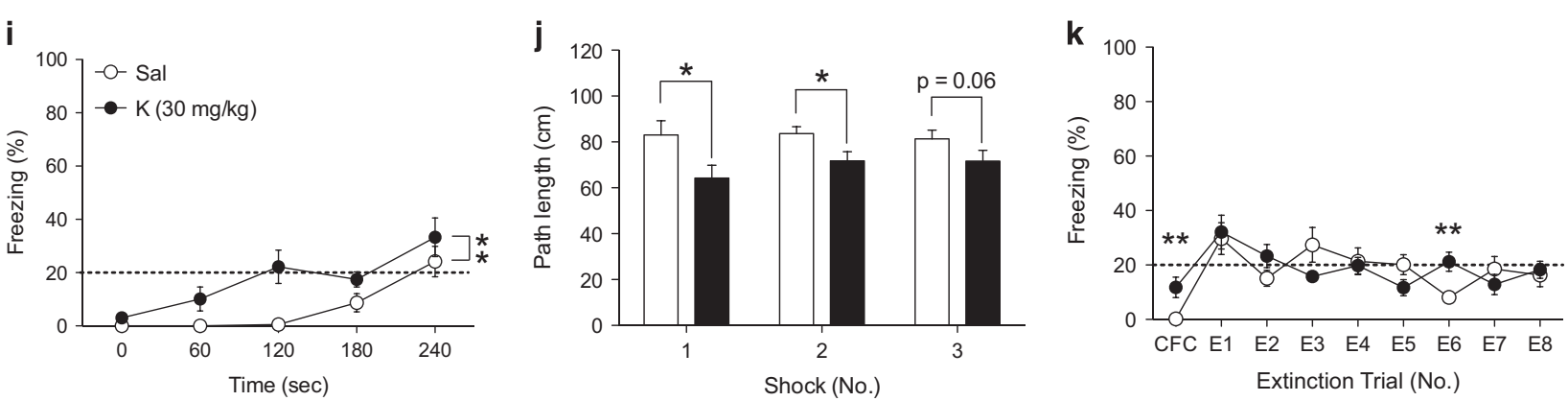

Figure 2 Prophylactic ketamine administration I month or $24 \mathrm{~h}$ before CFC does not result in a decreased fear response or facilitate extinction, but increases immobility if administered immediately before CFC. ( $a$ and b) Experimental design. (c) During CFC, mice injected with saline or ketamine I month before CFC displayed similar levels of freezing. (d) Both groups of mice traveled comparably during each of the 3 shock presentations. (e) Both groups of mice exhibited similar levels of freezing behavior during CFC training and during extinction ( $n=5$ mice per group). ( $f$ ) Mice injected with saline or with ketamine $24 \mathrm{~h}$ before CFC expressed equal levels of freezing behavior during CFC training. (g) Saline- and ketamine-injected mice traveled equally during the shock presentation. (h) Both groups of mice displayed similar levels of freezing behavior during all but one extinction trial ( $n=5$ mice per group). (i) During CFC, mice injected with ketamine I h prior have increased immobility before the shock presentation when compared with saline-injected mice. (j) Ketamineinjected mice travel less during the shock presentation than saline-injected mice. ( $k$ ) However, both groups express equal levels of freezing behavior during almost all extinction trials. ( $n=10$ mice per group). Error bars represent \pm SEM. $* p<0.05$, and ${ }^{*} * p<0.01$. CFC, contextual fear conditioning; , extinction; $K$, ketamine; $R$, reinstatement; $S a l$, saline. 
shock response (Figure 2d), and did not alter freezing behavior during extinction (Figure 2e) when compared with saline administration. These data indicate that there is a defined interval at which ketamine may be administered before a stressor, in order to buffer against fear expression.

\section{An Injection of Ketamine $24 \mathrm{~h}$ Before CFC Does Not Alter Fear Expression}

We next varied the interval immediately before CFC training. We first administered ketamine $24 \mathrm{~h}$ before CFC (Figure 2b). Ketamine administration did not alter immobility before the shock presentation, path length during the shocks, or freezing behavior during extinction (Figure $2 \mathrm{f}-\mathrm{h}$ ). However, there was a significant difference between saline and ketamine-injected mice on the last day of extinction (E8) $(p<0.02)$ (Figure $2 \mathrm{~h}$ ).

Next, we administered ketamine $1 \mathrm{~h}$ before CFC (Figure 2b). Ketamine administration resulted in increased immobility before the shock presentation (Figure 2i). Ketamine-injected mice traveled less during the shock presentations than saline-injected mice (Figure 2j). However, both groups of mice froze comparably during extinction, with the exception of E6 (Figure 2k). These data indicate that there is a defined window at which ketamine may be administered before a stressor, in order to buffer or decrease fear expression, and that administering too soon before a stressor may be problematic due to the analgesic effects.

\section{An Injection of Ketamine Following CFC or Before Extinction Does Not Alter Fear Expression}

To determine whether an injection of ketamine could alter fear extinction behavior following encoding, we next tested administration following $\mathrm{CFC}$ at various time points. Mice were injected with ketamine $1 \mathrm{~h}$ following three-shock CFC training (Figure 3a). A single injection of ketamine following CFC did not alter fear expression during extinction (Figure $3 b$ ).

Mice were then injected with ketamine 1 week following CFC, but 1 week before extinction, in order to mimic the 1-week interval that we use as a prophylactic (Figure 3c). A single injection of ketamine before extinction did not alter fear expression during extinction training (Figure $3 \mathrm{~d}$ ).

Lastly, mice were injected with ketamine $1 \mathrm{~h}$ before extinction (Figure 3e). A single injection of ketamine before extinction did not alter fear expression during extinction training (Figure 3f). These data suggest that ketamine administration following the encoding of a stressor does not alter the subsequent fear response.

\section{An Injection of Ketamine 1 Week Before Reinstatement Increases Attentiveness, But Does Not Decrease Fear Expression}

As our data indicated that that a single injection of ketamine 1 week before three-shock CFC reduces fear expression, we sought to determine whether ketamine administered before reinstatement would alter subsequent fear expression or alter behavior in other stressful paradigms (Figure 4a).

A single injection of ketamine 1 week before one-shock reinstatement did not alter subsequent fear expression
(Figure 4b). Saline- and ketamine-injected mice traveled comparably during the shock presentation given during reinstatement (Figure 4c). We next tested whether ketamine could alter stress-related behavior, as measured by behavioral despair in the FST or locomotion in the OF. Both groups of mice displayed similar time immobile in the FST (Figure 4d) and had comparable locomotion during the OF (Figure 4e). However, mice that received ketamine had a higher number of rearing bouts during the OF (Figure 4f). These data indicate that an injection of ketamine before one-shock reinstatement of a stressor does not buffer against fear expression. However, a single injection of ketamine before reinstatement increases attentiveness as measured by the number of rearing bouts in an OF.

We next wanted to determine whether the strength of the reinstatement experience influenced ketamine's effects on attentiveness described above. Here, ketamine was administered 1 week before a three-shock reinstatement trial instead of a one-shock reinstatement trial (Figure 4g). A single injection of ketamine 1 week before three-shock reinstatement did not alter fear expression (Figure 4h). Saline- and ketamine-injected mice traveled comparably during each of the three shock presentations (Figure 4i). As with the oneshock reinstatement experiment, both groups of mice displayed similar time immobile in the FST (Figure 4j) and basic movements during the OF (Figure 4k). In contrast to the one-shock reinstatement experiment, both groups had a comparable number of rearing bouts during the $\mathrm{OF}$ (Figure 4l) and these levels were similar to the salineinjected group described above (Figure 4f). These data indicate that an injection of ketamine before a strong reinstatement experience does not buffer against subsequent fear-inducing stimuli, or influence depressive-like or exploratory behavior in the FST and OF, respectively.

\section{An Injection of Ketamine Following Reinstatement Decreases Fear Following Three-shock CFC, but not One-shock CFC}

In order to determine whether administration of ketamine following reinstatement would influence subsequent fear expression, we next tested administration following the reinstatement experience at various time points. We first administered ketamine $1 \mathrm{~h}$ after a one-shock reinstatement paradigm (Figure 5a). A single injection of ketamine $1 \mathrm{~h}$ following a one-shock reinstatement did not alter subsequent fear expression (Figure 5b).

Ketamine was then administered $1 \mathrm{~h}$ after a three-shock reinstatement paradigm, in order to determine whether the strength of the reinstatement experience would influence differences in subsequent fear expression (Figure 5c). Interestingly, a single injection of ketamine $1 \mathrm{~h}$ after a three-shock reinstatement buffered fear expression during the first re-exposure and transiently decreased freezing throughout extinction (Figure 5d). We also tested ketamine administration at a $24 \mathrm{~h}$ time point following a three-shock reinstatement. A single injection of ketamine $24 \mathrm{~h}$ following three-shock reinstatement did not alter subsequent fear expression (Figure 5e). These data suggest that there is a limited time window following reinstatement during which ketamine may be effective in decreasing fear expression. 


\section{DISCUSSION}

Here, our results suggest that the timing of administering ketamine is critical for its effectiveness for buffering fear expression. We show that a single injection of ketamine administered 1 week before the start of CFC was most effective as a prophylactic in buffering against a heightened fear response during the first re-exposure to the aversive context. However, when administered at various other time points, it does not facilitate extinction or alter subsequent behavior. Ketamine administered 1 month or $1 \mathrm{~h}$ before the start of CFC does not buffer against a fear response or facilitate extinction. These data suggest that there is a limited time window for prophylactic protection. In addition, ketamine administered following CFC does not alter subsequent freezing levels. Yet, interestingly, ketamine administered $1 \mathrm{~h}$ after a strong reinstatement protocol a

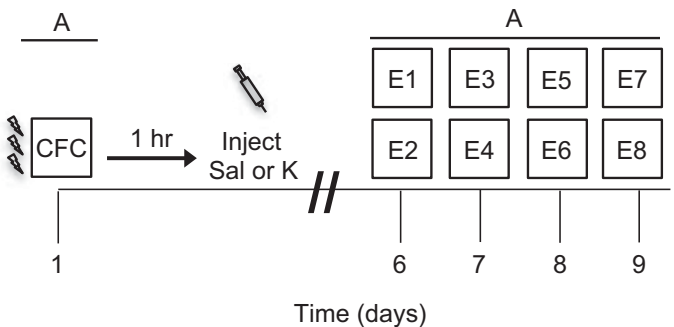

C

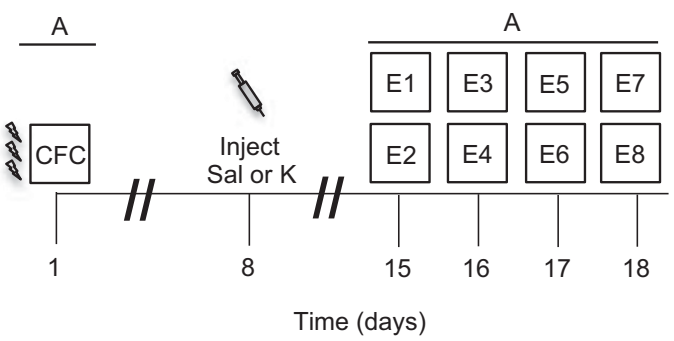

e

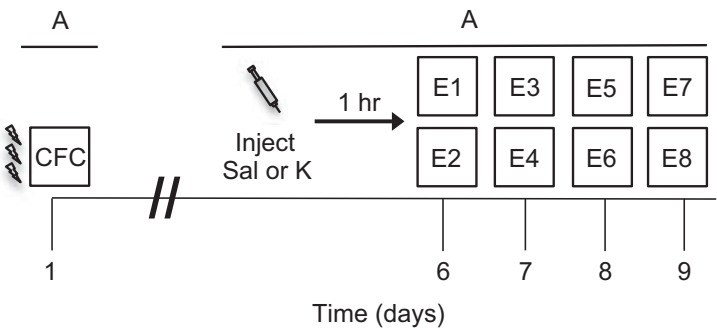

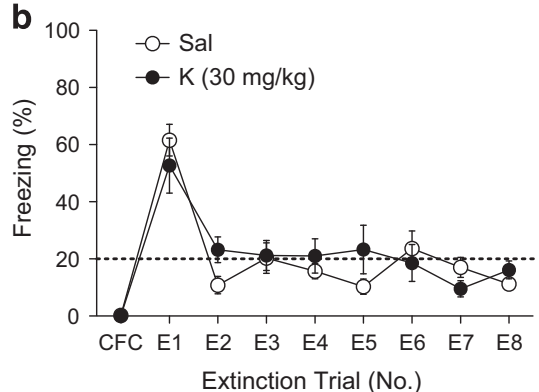

d
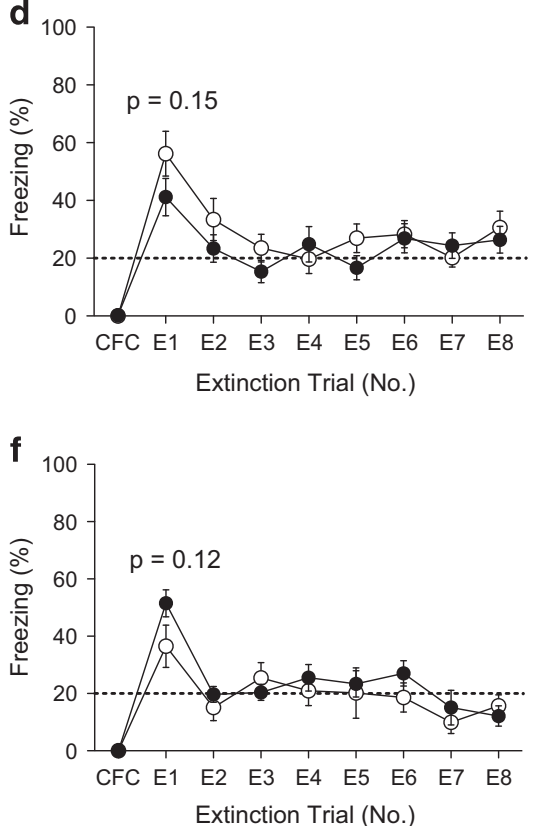

Figure 3 Ketamine administration does not facilitate extinction when administered following CFC. (a) Experimental design. (b) Mice injected with saline or with ketamine I $\mathrm{h}$ after CFC express equal levels of freezing behavior during all extinction trials ( $n=5$ mice per group). (c) Experimental design. (d) Mice injected with saline or with ketamine I week after CFC, but I week before extinction, expressed equal levels of freezing behavior during all extinction trials ( $n=10$ mice per group). (e) Experimental design. ( $f$ ) Mice injected with saline or with ketamine I h before extinction expressed equal levels of freezing behavior during all extinction trials ( $n=5$ mice per group). Error bars represent \pm SEM. CFC, contextual fear conditioning; $E$, extinction; K, ketamine; $R$, reinstatement; Sal, saline.

Figure 4 Ketamine administration following extinction does not buffer against subsequent fear-inducing stimuli but increases attentiveness. (a) Experimental design. (b) Mice injected with saline or with ketamine $24 \mathrm{~h}$ after the last extinction trial expressed equal levels of freezing behavior during reinstatement and during secondary extinction trials. (c) Both groups of mice traveled comparably during the reinstatement shock presentation. (d) Both groups of mice exhibited equal levels of immobility in the FST on day I and on day 2. (e) Both groups of mice exhibited equal levels of movement in the OF. (f) Ketamine-injected mice displayed an increased number of rearing bouts when compared with saline-injected mice ( $n=5$ mice per group). (g) Experimental design. ( $h$ ) Saline and ketamine-injected mice displayed comparable levels of fear behavior during reinstatement and during secondary extinction trials. (i) Both groups of mice traveled comparably during each of the 3 reinstatement shock presentations. (j) Both groups of mice exhibit equal levels of immobility in the FST on day I and on day 2. ( $k$ and I) Both groups of mice exhibited equal levels of movement in the OF and had a comparable number of rearing bouts $(n=9-10$ mice per group). Error bars represent \pm SEM. ${ }^{*} p<0.05$. CFC, contextual fear conditioning; E, extinction; FST, forced swim test; K, ketamine; OF, open field; R, reinstatement; Sal, saline. 
decreased fear expression, suggesting a potential window of efficacy. Lastly, ketamine administration following extinction but before reinstatement does not alter freezing levels, yet it increases rearing in the OF, a possible measure of attentiveness. This increase in rearing in the $\mathrm{OF}$ is abolished following a strong reinstatement paradigm, indicating that the intensity of the stressor influences the effectiveness of ketamine on rearing.

a

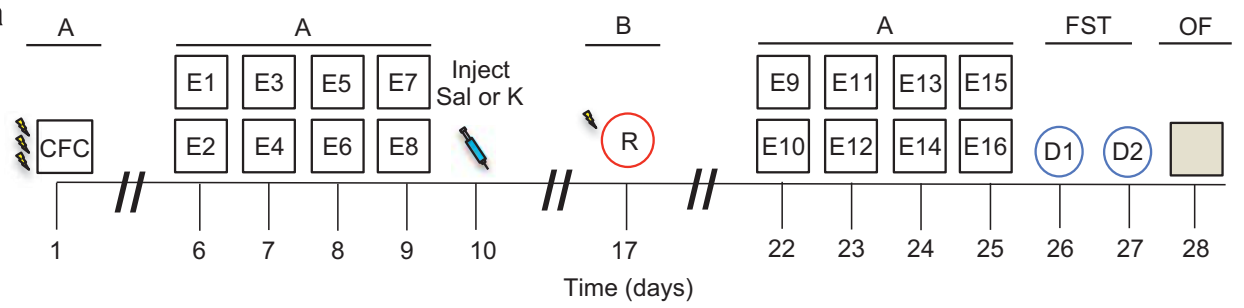

b
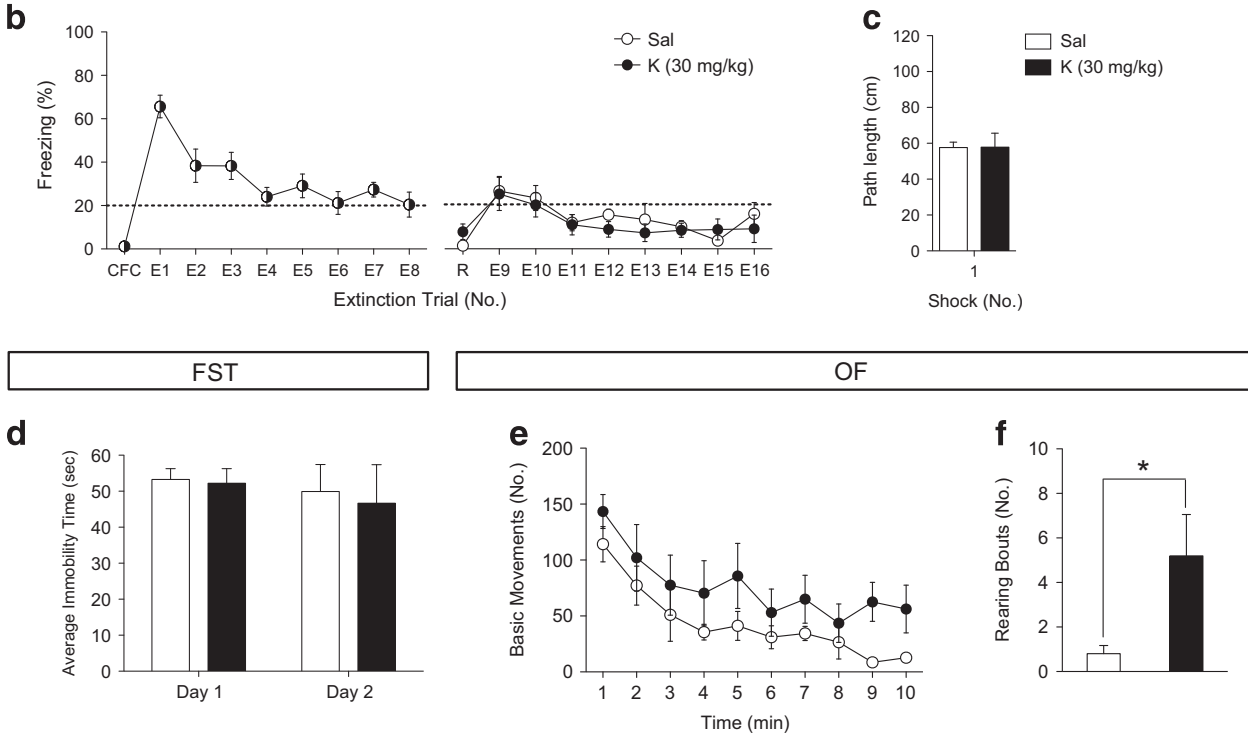

9

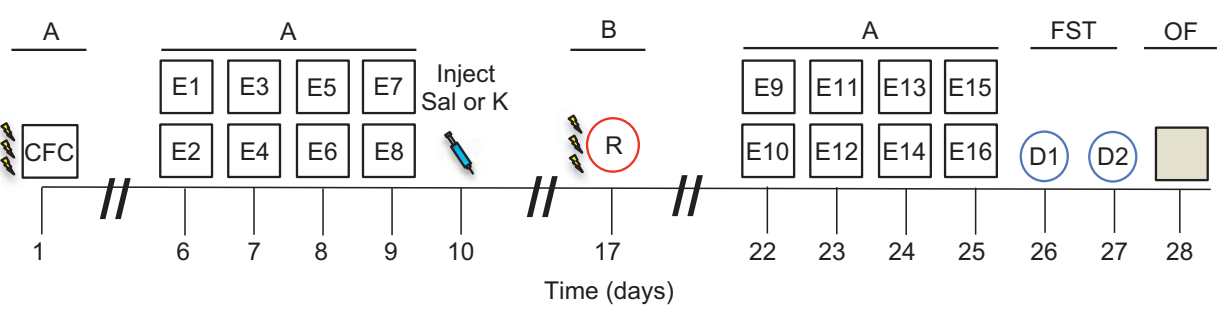

h
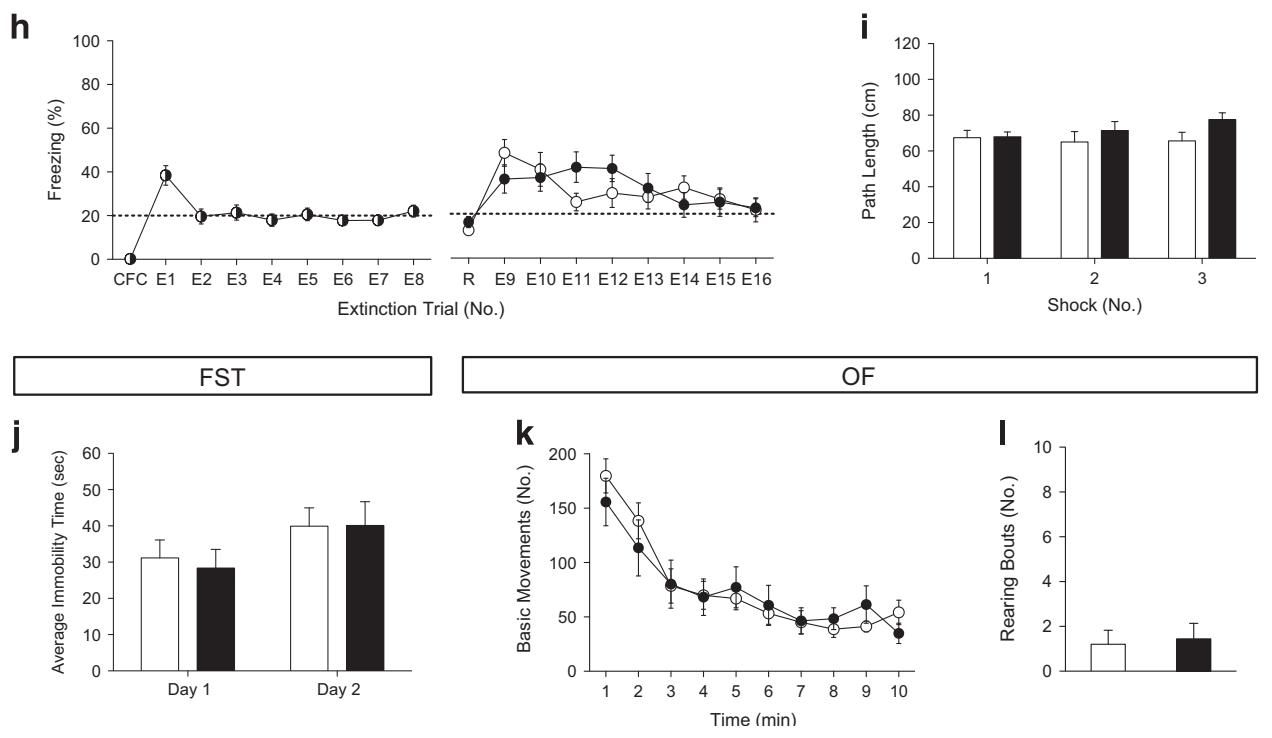
The prophylactic effect that we have previously reported in three different models of stress was replicated here (Brachman et al, 2016). We initially reported that ketamine administered 1 week before social defeat, learned helplessness, or chronic corticosterone protected against depressive-like behavior. Here we see a similar effect by using CFC as a stressor: prophylactic ketamine buffers the stress response upon the first re-exposure to the fearful context when administered 1 week before CFC training. Although ketamine's effects on fear extinction cannot be concluded due to the initially low level of freezing, it is notable that ketamine decreases fear expression. However, we do not exclude the possibility that prophylactic ketamine may impair the acquisition of fear or impair memory retrieval when administered at the 1-week time point. Future studies will address this possibility.

Ketamine's prophylactic efficacy is dependent on when it is administered before a fear-inducing stimulus, as a protection was not observed at the 1-month time point. These data are in accord with a recent study showing that ketamine administered up to 2 weeks before an inescapable stressor blunted the neurochemical effects of the stressor (Amat et al, 2016). Therefore, there is likely a defined window as to when ketamine may confer its most effective therapeutic potential.

Surprisingly, administering ketamine $24 \mathrm{~h}$ before the stressor did not induce a prophylactic effect on fear expression, indicating that this effect is restricted to about one week before the stressor. Yet, it is currently unknown whether there is an intermediate time point between $24 \mathrm{~h}$ and 1 week that also allows for prophylactic efficacy. In interpreting these data within a clinical framework, it is crucial to consider that the time course of drug efficacy from a mouse model to a human may not be precisely matched. It is likely, however, that there is a similar defined time window of therapeutic efficacy in humans.

It is interesting to note that ketamine administered immediately before CFC resulted in increased immobility and a blunted response to the shocks. This effect was seen only when ketamine was administered $1 \mathrm{~h}$, but not $24 \mathrm{~h}$ before CFC. This increase in immobility is most likely due to altered pain sensitivity as it has been reported that following an i.p. injection of ketamine, animals have an increased reaction time to the hot plate test (Takahashi et al, 1986). These data show that acute ketamine administration induces an analgesic effect. In contrast to our findings that ketamine affects time immobile when administered $1 \mathrm{~h}$ before CFC, it is notable that the present study did not observe increased freezing or blunted response to the shocks when ketamine was administered $24 \mathrm{~h}$ before CFC. It is likely that the analgesic effects of the drug persist for $1 \mathrm{~h}$, but not $24 \mathrm{~h}$ post injection, as ketamine is known to have a half-life of approximately $2.5 \mathrm{~h}$ (Wieber et al, 1975). Thus, administering ketamine immediately before a stressor may interfere with the perception of pain during a stressor.

An additional interpretation of increased freezing during CFC may be that ketamine is affecting locomotor activity in mice shortly after administration. Several studies found that NMDAR antagonists including ketamine and $S$-ketamine induced hyperactivity shortly after administration (Refsgaard et al, 2016; Razoux et al, 2007). Yet, one study found no effects of ketamine on locomotor activity in rats (Moosavi et al, 2012), indicating that the timing of administration as well as the ketamine dosage are key components in determining its effects on locomotion. Thus, here ketamine's effects may be either sensory, motor, or a combination of both. As ketamine has also been found to influence memory, particularly plasticity mechanisms within the hippocampus (Ardalan et al, 2016a, b; Jett et al, 2015), it is possible that the increased freezing observed at one of the subsequent extinction sessions could indicate ketamine's effect on heightening the memory of the aversive context. A recent study demonstrated that fear memories reactivated under ketamine were subsequently stronger (Honsberger et al, 2015). Further studies are necessary to validate this potential phenomenon.

To extend the earlier PTSD and ketamine studies in US service members (McGhee et al, 2008; McGhee et al, 2014) to rodent models, we administered ketamine $1 \mathrm{~h}$ after CFC, 1 week after CFC, or $1 \mathrm{~h}$ before extinction training. Although the initial McGhee study (McGhee et al, 2008) found a reduction in the incidence of $\mathrm{PTSD}$, the later study found a comparable incidence rate of PTSD in US military personnel treated with and without intraoperative ketamine (McGhee et al, 2014). Our findings are in agreement with the later study-we did not find post-exposure administration to be effective in reducing the fear response. These results align with our previous data (Brachman et al, 2016) in which ketamine administered following a stressor did not prevent against stress-induced depressive-like behaviors and with a previous rodent study in rats which found that immediate ketamine treatment following a stressor did not prevent the onset of PTSD (Juven-Wetzler et al, 2014). It is essential to consider, however, the variable histories of the patients treated in both McGhee studies. While our rodent studies correlate with findings that suggest ketamine is not effective in preventing the onset of PTSD when administered immediately after the trauma, we believe that the history and individual timing of the ketamine administration is critical in determining the effectiveness of the treatment.

We found that ketamine 1 week before a one-shock reinstatement paradigm did not alter fear expression, contrary to the effect of prophylactic ketamine 1 week before CFC. It is important to note that the one-shock reinstatement CFC protocol used throughout this study is weak compared to the three-shock reinstatement CFC protocol,

\footnotetext{
Figure 5 Ketamine administration following reinstatement decreases fear following three-shock CFC, but not one-shock CFC. (a) Experimental design. (b)

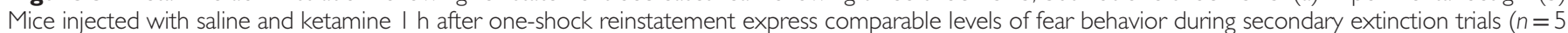

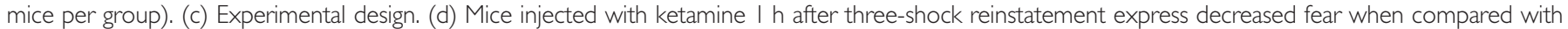

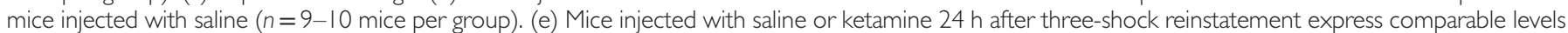

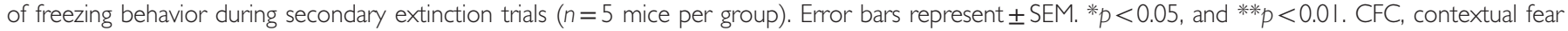
conditioning; E, extinction; K, ketamine; R, reinstatement; Sal, saline.
} 
and takes place within a distinct yet similar context as the original CFC context. Thus, out data may show altered reconsolidation of the original fear memory, but it is also possible that the mice are experiencing fear generalization in the reinstatement context. Yet, despite these caveats, these data primarily demonstrate that ketamine is most effective

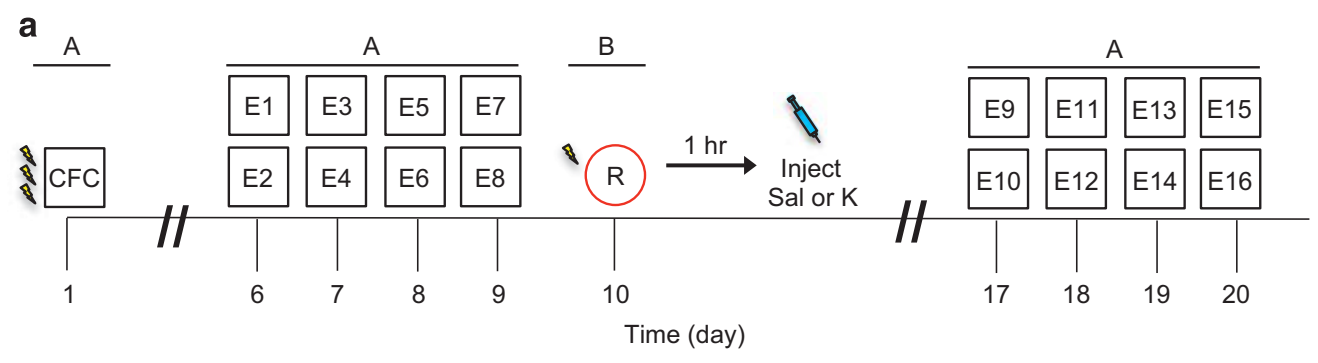

$1 \mathrm{~h}$ after $\mathrm{R}$
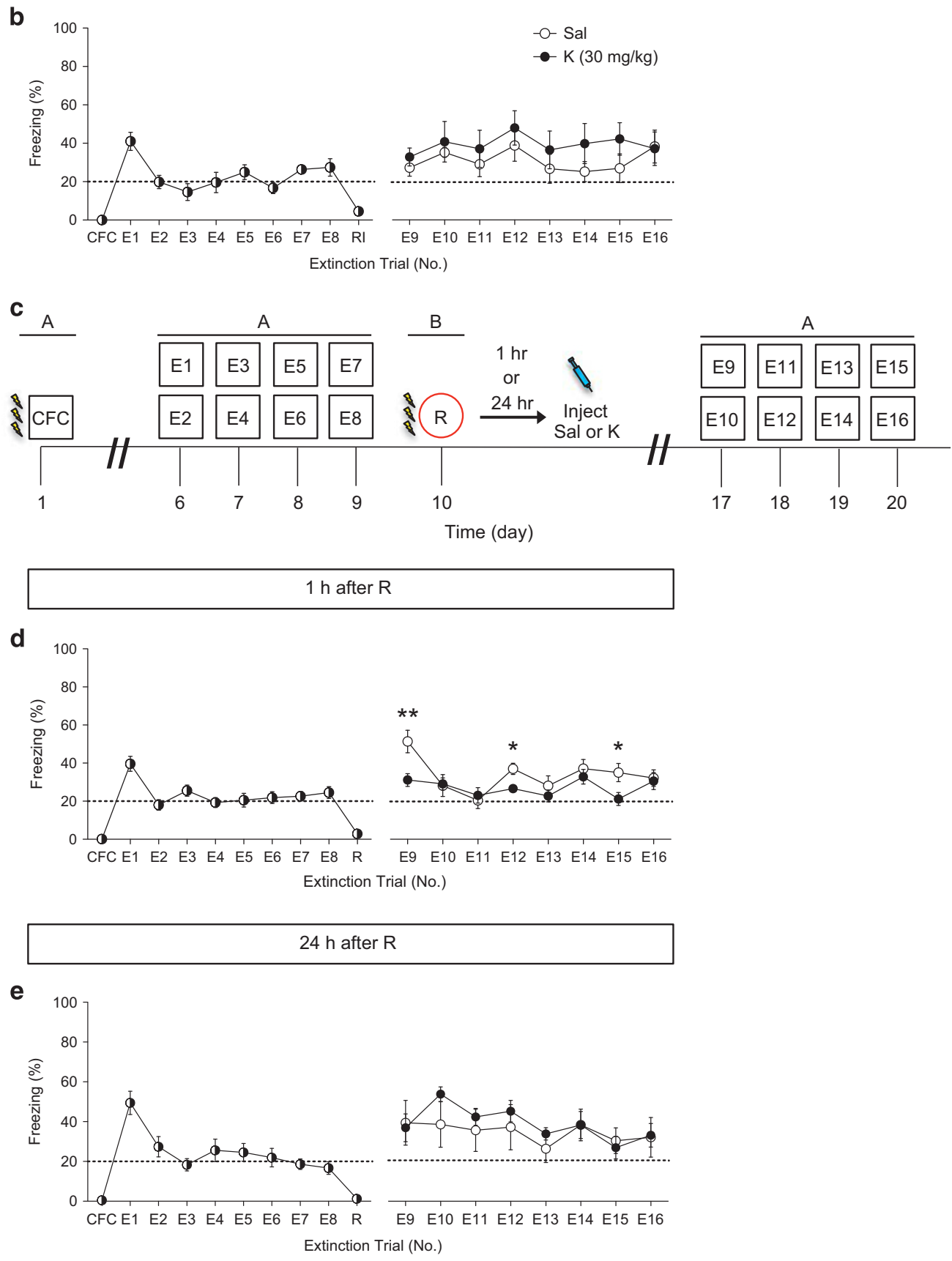
when administered as a prophylactic before a stressor rather than before reinstatement of the stressor, consistent with what is known about primary prophylaxis. Furthermore, it suggests that previous stressors influence subsequent stressor responses.

Although ketamine administration did not affect locomotion in the OF, it did increase the number of rearing bouts. It has been suggested that rodents' rearing on hind legs can be a measure of attentive behavior, as it demonstrates increased interest in the spatial environment, as well as a lower perceived threat (Lever et al, 2006). However, there is a scarcity of analysis on the significance of rearing in rodents for anxiolytic behaviors, though it is often interpreted as an exploratory response to novel stimuli (Van Abeelen, 1975; Crusio, 2001). It remains to be determined whether increased attentiveness to one's surroundings may be a positive outcome as opposed to a negative outcome indicating increased anxiety. Yet, more recently, a five-choice continuous performance test has been adapted from human studies to rodents in order to assess attentive behavior as a measure of vigilance (Young et al, 2009). Future studies utilizing the 5C-CBT may further validate whether ketamine increases vigilant-like attentive behavior when administered as a prophylactic.

There was similarly no effect on fear expression or on depressive-like behavior in the FST when ketamine was administered 1 week before a stronger reinstatement (threeshock CFC). Surprisingly, however, an increase in rearing behavior was not observed in this experiment. These data suggest that the aversive value of the traumatic experience may play a critical role in effectiveness of therapy. It has been suggested that the intensity of the unconditioned stimulus has a direct correlation to the severity of PTSD symptomology (Buydens-Branchey et al, 1990; Yehuda et al, 1992; Norrholm et al, 2011). However, it is more difficult to define stressor severity in humans, given the wide range of criterion that may define a stressor (ie, witnessing a trauma $v s$ experiencing one) (Long et al, 2008), as well as the subjective distress of the stressor experienced (Feinstein and Dolan, 1991; O'Hare et al, 2006). However, future work should consider the severity of the stressor in relation to the effectiveness of treatments or preventions for PTSD.

Administering ketamine $1 \mathrm{~h}$ after a relatively weak (one-shock) reinstatement did not have effects on fear expression or extinction. This finding agrees with previous studies demonstrating that ketamine did not alleviate symptoms of PTSD when given shortly after a trauma (McGhee et al, 2014; Juven-Wetzler et al, 2014). Interestingly, several studies have speculated that ketamine administered immediately after a strong traumatic incident may enhance fear expression after a single dose (Schönenberg et al, 2005, 2008) or multiple doses (Winter and Irle, 2004). Overall, it is probable that administering ketamine after reexperiencing the trauma is directly acting on reconsolidation mechanisms. Notably, Schiller et al, 2010 have proposed that reconsolidation is a window of opportunity to rewrite emotional memories.

Interestingly, when ketamine was administered $1 \mathrm{~h}$ after a stronger reinstatement trial (three-shock CFC), ketamine decreased subsequent fear expression during extinction, indicating that ketamine may indeed be having an effect on memory consolidation. In considering ketamine's effects on memory consolidation, ketamine may be having a similar effect as propranolol, a beta-blocker. Previous data have shown that propranolol may be effective as a treatment for PTSD when administered during the reconsolidation window (Laverdure and Boulenger, 1991; Taylor and Cahill, 2002; Pitman et al, 2002; Vaiva et al, 2003; Henry et al, 2007; Soeter and Kindt, 2015; Villain et al, 2016). Yet, it is intriguing that recent studies and meta-analyses suggest that the drug may not be reliably effective (McGhee et al, 2009; Muravieva and Alberini, 2010; Cohen et al, 2011; Argolo et al, 2015; Steenan et al, 2016). In light of this field of investigation, however, our data suggest that ketamine may also disrupt consolidation of aversive memories in specific conditions, such as in conditions that robustly activate the fear system.

In regards to ketamine's potential effect on fear memory, it is important to note that NMDA receptor antagonists similar to ketamine have been shown to have effects on fear behavior. The effects demonstrated in our study are similar to previous studies involving NMDA receptor antagonists on acquisition. For example, Fanselow and Kim, 1994 assessed the effect of infusing the NMDA receptor antagonist D,L-2amino-5-phosphonovaleric acid (APV) into the basolateral region of the amygdala before CFC. They found that an APV infusion prevented the acquisition of fear. A similar study recapitulated these results with the NMDA antagonist AP5: infusing AP5 into the amygdala blocks acquisition, but not expression, of fear conditioning (Miserendino et al, 1990). Another group demonstrated that micro-infusion of AP5 to the amygdala blocked second-order fear conditioning (Gewirtz and Davis, 1997). There also appears to be evidence for the role of NMDA receptors in extinction. The noncompetitive NMDA antagonist MK-801 was shown to block extinction in a dose-dependent manner (Baker and Azorlosa, 1996). However, no previous group has administered ketamine as far in advanced as the current study has to assess fear expression. It is likely that separate mechanisms as well as NMDA receptor modulation mediate ketamine's prophylactic effect. Studies are currently ongoing to probe the mechanistic actions of this protective quality.

Overall, this study suggests that ketamine may be most effective in buffering fear responsive when administered as a prophylactic 1 week before a stressor. However, the use of CFC as a measure of a deleterious fear response merits further discussion. Exacerbated fear memory is a characteristic of the psychopathology of PTSD. The fear memory is often persistent, owing to a dysregulation of extinction and reconsolidation (Careaga et al, 2016; Wicking et al, 2016). The CFC paradigm utilized in this study attempts to mimic the onset of traumatic memory. Yet, although we utilize heightened fear expression as a measure of maladaptive fear characteristic of PTSD, it has been suggested that the fear response in rodents is adaptive behavior in response to expected threat (Bailey and Crawley, 2009). Furthermore, the use of a single three-shock paradigm induces a heightened fear response, but other models may induce a more salient traumatic memory. As the fear response here may be modeling aspects of adaptive fear learning, additional models such as stress-enhanced fear learning should be utilized in future studies (Rau and Fanselow, 2009).

To our knowledge, this study is the first demonstration of a critical time window to administer ketamine for 
stress-induced psychiatric disease. We propose that ketamine may be most effective when administered in a vaccine-like manner, but only within a particular time window before the stressor. Ketamine treatment could also enhance attentiveness to one's surroundings as long as 2 weeks following administration. Yet, these data indicate that it would not be ideal to administer ketamine shortly after a traumatic experience, although there may be benefits to administering it shortly after a strong reinstatement, possibly due to effects on ketamine in the reconsolidation of a fear memory, though the exact mechanisms of this effect remain to be discovered. Ultimately, we propose these data as a guide for interpreting past and future studies on ketamine's effectiveness for mood disorders.

\section{FUNDING AND DISCLOSURE}

JCM, CTL, MT, SCL and YN reported no biomedical financial interests or potential conflicts of interest. RAB and $\mathrm{CAD}$ are named on a provisional patent application for the prophylactic use of ketamine against stress-related psychiatric disorders.

\section{ACKNOWLEDGMENTS}

We thank members of the laboratory for insightful comments on this project and manuscript. JCM was supported by the Barnard Noyce Teacher Scholars Program, a Columbia University Summer Undergraduate Research Fellowship (SURF), and the Columbia University Summer Program for Under-Represented Students (SPURS). CTL was supported by Barnard College's Summer Research Institute (SRI). SCL was supported by a NIH DP5 OD017908-01. CAD was supported by a NIH DP5 OD017908-01, a NYSTEM C-021957, and a NARSAD Young Investigator Grant from the Brain \& Behavior Research Foundation, P\&S Investigator.

\section{REFERENCES}

Amat J, Dolzani SD, Tilden S, Christianson JP, Kubala KH, Bartholomay K et al (2016). Previous ketamine produces an enduring blockage of neurochemical and behavioral effects of uncontrollable stress. J Neurosci 36: 153-161.

Ardalan M, Wegener G, Polsinelli B, Madsen TM, Nyengaard JR (2016a). Neurovascular plasticity of the hippocampus one week after a single dose of ketamine in genetic rat model of depression. Hippocampus 26: 1414-1423.

Ardalan M, Wegener G, Rafati AH, Nyengaard JR (2016b). S-ketamine rapidly reverses synaptic and vascular deficits of hippocampus in genetic animal model of depression. Int $J$ Neuropsychopharmacol (in press).

Argolo FC, Cavalcanti-Ribeiro P, Netto LR, Quarantini LC (2015). Prevention of posttraumatic stress disorder with propranolol: a meta-analytic review. J Psychosom Res 79: 89-93.

Bailey KR, Crawley JN. Anxiety-related behaviors in mice. In: Buccafusco, JJ (ed.). Methods of Behavior Analysis in Neuroscience, Chapter 5: CRC Press/Taylor \& Francis; 2009 (Boca Raton, FL).

Baker JD, Azorlosa JL (1996). The NMDA antagonist MK-801 blocks the extinction of Pavlovian fear conditioning. Behav Neurosci 110: 618-620.

Berman RM, Cappiello A, Anand A, Oren DA, Heninger GR, Charney DS et al (2000). Antidepressant effects of ketamine in depressed patients. Biol Psychiatry 47: 351-354.
Bernardini F, Attademo L, Cleary SD, Luter C, Shim RS, Quartesan R et al (2016). Risk prediction models in psychiatry: toward a new frontier for the prevention of mental illnesses. J Clin Psychiatry (in press).

Brachman RA, McGowan JC, Perusini JN, Lim SC, Plam TH, Faye $C$ et al (2016). Ketamine as a prophylactic against stressinduced depressive-like behavior. Biol Psychiatry 79: 776-786.

Buydens-Branchey L, Noumair D, Branchey M (1990). Duration and intensity of combat exposure and posttraumatic stress disorder in Vietnam veterans. J Nerv Ment Dis 178: 582-587.

Careaga MBL, Girardi CEN, Suchecki D (2016). Understanding posttraumatic stress disorder through fear conditioning, extinction, and reconsolidation. Neurosci Biobehav Rev 71: 48-57.

Charney DS, Deutch AY, Krystal JH, Southwick SM, Davis M (1993). Psychobiologic mechanisms of posttraumatic stress disorder. Arch Gen Psychiatry 50: 295-305.

Cohen H, Kaplan Z, Koresh O, Matar MA, Geva AB, Zohar J (2011). Early post-stressor intervention with propranolol is ineffective in preventing posttraumatic stress responses in animal model for PTSD. Eur Neuropsychopharmacol 21: 230-240.

Crusio WE (2001). Genetic dissection of mouse exploratory behavior. Beh Brain Res 125: 127-132.

Denny CA, Burghardt NS, Schachter DM, Hen R, Drew MR (2012). 4- to 6-week-old adult-born hippocampal neurons influence novelty- evoked exploration and contextual fear conditioning. Hippocampus 22: 1188-1201.

Denny CA, Kheirbek MA, Alba EL, Tanaka KF, Brachman RA, Laughman KB et al (2014). Hippocampal memory traces are differentially modulated by experience, time, and adult neurogenesis. Neuron 83: 189-201.

Drew MR, Denny CA, Hen R (2010). Arrest of adult hippocampal neurogenesis in mice impairs single- but not multiple-trial contextual fear conditioning. Behav Neurosci 124: 446-454.

Fanselow MS, Kim JJ (1994). Acquisition of contextual Pavlovian fear conditioning is blocked by application of an NMDA receptor antagonist D,L-2-amino-5-phosphonovaleric acid to the basolateral amygdala. Behav Neurosci 108: 210-212.

Feder A, Parides MK, Murrough JW, Perez AM, Morgan JE, Sazena S et al (2014). Efficacy of intravenous ketamine for treatment of chronic posttraumatic stress disorder. JAMA Psychiatry 71: 681-688.

Feinstein A, Dolan R (1991). Predictors of post-traumatic stress disorder following physical trauma: an examination of the stressor criterion. Psychol Med 21: 85-91.

Gewirtz JC, Davis M (1997). Second-order fear conditioning prevented by blocking NMDA receptors in amygdala. Nature 388: 471-474.

Golub Y, Mauch CP, Dahlhoff M, Wotjac CT (2009). Consequences of extinction training on associative and non-associative fear in a mouse model of Posttraumatic Stress Disorder (PTSD). Behav Brain Res 205: 544-549.

Henry M, Fishman JR, Youngner SJ (2007). Propranolol and the prevention of post-traumatic stress disorder: is it wrong to erase the 'sting' of bad memories? Am J Bioeth 7: 12-20.

Hofmann SG, Sawyer AT, Witt AA, Oh D (2010). The effect of mindfulness-based therapy on anxiety and depression: a metaanalytic review. J Consult Clin Psychol 78: 169-183.

Honsberger MJ, Taylor JR, Corlett PR (2015). Memories reactivated under ketamine are subsequently stronger: a potential pre-clinical behavioral model of psychosis. Schizophr Res 164: 227-233.

Horn SR, Charney DS, Feder A (2016). Understanding resilience: New approaches for preventing and treating PTSD. Exp Neurol 284: 119-132.

Jett JD, Boley AM, Girotti M, Shah A, Lodge DJ, Morilak DA (2015). Antidpressant-like cognitive and behavioral effects of acute ketamine administration associated with plasticity in the ventral hippocampus to medial prefrontal cortex pathway. Psychopharmacology (Berl) 232: 312-333.

Juven-Wetzler A, Cohen H, Kaplan Z, Kohen A, Porat O, Zohar J (2014). Immediate ketamine treatment does not prevent 
posttraumatic stress responses in an animal model for PTSD. Eur Neuropsychopharmacol 24: 469-479.

Kessler RC, Chiu WT, Demler O, Mirkangas KR, Walters EE (2005). Prevalence, severity, and comorbidity of 12-month DSM-IV disorders in the National Comorbidity Survey Replication. Arch Gen Psychiatry 62: 617-627.

Kessler RC, Sonnega A, Bromet E, Hughes M, Nelson CB (1995). Posttraumatic stress disorder in the National Comorbidity Survey. Arch Gen Psychiatry 52: 1048-1060.

Laverdure B, Boulenger JP (1991). Beta-blocking drugs and anxiety: a proven therapeutic value. Encephale 17: 481-492.

Lever C, Burton S, O'Keefe J (2006). Rearing on hind legs, environmental novelty, and the hippocampal function. Rev Neurosci 17: 111-133.

Long ME, Elhai JD, Schweinle A, Gray MJ, Grubaugh AL, Frueh BC (2008). Differences in posttraumatic stress disorder diagnosistic rates and symptom severity between Criterion A1 and nonCriterion A1 stressors. J Anxiety Disord 22: 1255-1263.

Lubin H, Loris M, Burt J, Johnson DR (1998). Efficacy of psychoeducational group therapy in reducing symptoms of posttraumatic stress disorder among multiply traumatized women. Am J Psychiatry 155: 1172-1177.

McGhee LL, Maani CV, Garza TH, Gaylord KM, Black IH (2008). The correlation between ketamine and posttraumatic stress disorder in burned service members. J Trauma 64: S195-S198.

McGhee LL, Maani CV, Garza TH, DeSocio PA, Gaylord KM, Black IH (2009). The effect of propranolol on posttraumatic stress disorder in burned service members. J Burn Care Res 30: 92-97.

McGhee LL, Maani CV, Garza TH, Slater TM, Petz LN, Fowler M (2014). The intraoperative administration of ketamine to burned U.S. service members does not increase the incidence of posttraumatic stress disorder. Mil Med 179: 41-46.

Miserendino MJ, Sananes CB, Melia KR, Davis M (1990). Blocking of acquisition but not expression of conditioned fear-potentiated startle by NMDA antagonists in the amygdala. Nature 345: 716-718.

Moosavi M, Khales GY, Rastegar K, Zarifkar A (2012). The effect of sub-anesthetic and anesthetic ketamine on water maze memory acquisition, consolidation and retrieval. Eur J Pharmacol 677: 107-110.

Murrough JW, Iosifescu DV, Chang LC, Al Jurdi RK, Green CE, Perez AM et al (2013). Antidepressant efficacy of ketamine in treatment-resistant major depression: a two-site randomized controlled trial. Am J Psychiatry 170: 1134-1142.

Muravieva EV, Alberini CM (2010). Limited efficacy of propranolol on the reconsolidation of fear memories. Learn Mem 17: 306-313.

National Center for PTSD (2015). How common is PTSD? U.S. Department of Veterans Affairs, National Center for PTSD.

Norrholm SD, Jovanovic T, Olin IW, Sands LAKarapanou I, Bradley B, Ressler KJ (2011). Fear exinction in traumatized civilians with posttraumatic stress disorder. Biol Psychiatry 15: 556-563.

O'Hare T, Sherrer MV, Shen C (2006). Subjective distress from stressful events and high-risk behaviors as predictors of PTSD symptom severity in clients with severe mental illness. J Trauma Stress 19: 375-386.

Pitman RK, Sanders KM, Zusman RM, Healy AR, Cheema F, Lasko NB et al (2002). Pilot study of secondary prevention of posttraumatic stress disorder with propranolol. Biol Psychiatry 51: 189-192.

Pradhan B, D’Amico JK, Makani R, Parikh T (2016). Nonconventional interventions for chronic post-traumatic stress disorder: ketamine, repetitive trans-cranial magnetic stimulation (Rtms), and alternative approaches. J Trauma Dissociation 17: 35-54.

Price RB (2016). From mice to men: can ketamine enhance resilience to stress? Biol Psychiatry 79: e57-e59.
Rau V, Fanselow MS (2009). Exposure to a stressor produces a long lasting enhancement of fear learning in rats. Stress 12: 125-133.

Razoux F, Garcia R, Léna I (2007). Ketamine, at a dose that disrupts motor behavior and latent inhibition, enhances prefrontal cortex synaptic efficacy and glutamate release in the nucleus accumbens. Neuropsychopharmacology 32: 719-727.

Refsgaard LK, Pickering DS, Andreasen JT (2016). Investigation of antidepressant-like and anxiolytic-like actions and cognitive and motor side effects of four $N$-methyl-D-aspartate receptor antagonists in mice. Behav Pharmacol 28: 37-47.

Richardson-Jones JW, Craige CP, Guiard BP, Stephen A, Metzger KL, Kung HF et al (2010). 5-HT1A autoreceptor levels determine vulnerability to stress and response to antidepressants. Neuron 65: 40-52.

Sananbenesi F, Fischer A, Wang X, Schrick C, Neve R, Radulovic J et al (2007). A hippocampal Cdk5 pathway regulates extinction of contextual fear. Nat Neurosci 10: 1012-1019.

Schiller D, Monfils MH, Raio CM, Johnson DC, LeDoux JE, Phelps EA (2010). Preventing the return of fear in humans using reconsolidation update mechanisms. Nature 463: 49-53.

Schönenberg M, Reichwald U, Domes G, Badke A, Hautzinger M (2005). Effects of peritraumatic ketamine medication on early and sustained posttraumatic stress symptoms in moderately injured accident victims. Psychopharmacol 182: 420-425.

Schönenberg M, Reichwald U, Domes G, Badke A, Hautzinger M (2008). Ketamine aggravates symptoms of acute stress disorder in a naturalistic sample of accident victims. J Psychopharm 22: 493-497.

Shapiro F (1989). Eye movement desensitization: a new treatment for post-traumatic stress disorder. J Behav Ther Exp Psychiatry 20: 211-217.

Skeffington PM, Rees CS, Mazzucchelli TG, Kane RT (2016). The primary prevention of PTSD in firefighters: preliminary results of an RCT with 12-month follow-up. PLoS ONE 11: e0155873.

Soeter M, Kindt M (2015). An abrupt transformation of phobic behavior after a post-retrieval amnesic agent. Biol Psychiatry 78: 880-886.

Steenan SA, van Wijk AJ, van der Heijden GJMG, van Westrhenen R, de Lange J, de Jongh A (2016). Propranolol for the treatment of anxiety disorders: systematic review and meta-analysis. J Psychopharm 30: 128-139.

Steenkamp MM, Litz BT, Hoge CW, Marmar CR (2015). Psychotherapy for military-related PTSD: A review of randomized clinical trials. JAMA 314: 489-500.

Stein DJ, Ipser JC, Seedat S (2006). Pharmacotherapy for post traumatic stress disorder (PTSD). Cochrane Database Syst Rev CD002795.

Takahashi RN, Morato GS, Rae GA (1986). Effects of ketamine on nociception and gastrointestinal motility in mice are unaffected by naloxone. Gen Pharmacol 18: 201-203.

Taylor F, Cahill L (2002). Propranolol for reemergent posttraumatic stress disorder following an event of retraumatization: A case study. J Trauma Stress 433-437.

Trouch S, Sasaki JM, Tu T, Reijmers LG (2013). Fear extinction causes target-specific remodeling of perisomatic inhibitory synapses. Neuron 80: 1054-1065.

Vaiva G, Ducrocq F, Jezequel K, Averland B, Lestavel P, Brunet A et al (2003). Immediate treatment with propranolol decreases posttraumatic stress disorder two months after trauma. Biol Psychiatry 54: 947-949.

Van Abeelen JHF (1975). Genetic analysis of behavioural responses to novelty in mice. Nature 254: 239-241.

Villain H, Benkahoul A, Drougard A, Lafragette M, Muzotte E, Pech $S$ et al (2016). Effects of propranolol, a $\beta$-noradrenergic antagonist, on memory consolidation and reconsolidation in mice. Front Behav Neurosci 10: 49.

Wald I, Fruchter E, Ginat K, Stolin E, Dagan D, Bliese PD et al (2016). Selective prevention of combat-related post-traumatic 
stress disorder using attention bias modification training: A randomized controlled trial. Psychol Med 46: 2627-2636.

Wicking M, Steger F, Nees F, Diener SJ, Grimm O, Ruttorf M et al (2016). Deficient fear extinction memory in posttraumatic stress disorder. Neurobiol Learn Mem 136: 116-126.

Wieber J, Gugler R, Hengstmann JG, Dengler HJ (1975). Pharmacokinetics of ketamine in man. Anaesthesist 24: 260-263.

Winter H, Irle E (2004). Hippocampal volume in adult burn patients with and without posttraumatic stress disorder. Am J Psychiatry 161: 2194-2200.
Yehuda R, Southwick SM, Giller EL (1992). Exposure to atrocities and severity of chronic posttraumatic stress disorder in Vietnam combat veterans. Am J Psychiatry 149: 333-336.

Young JW, Light GA, Marston HM, Sharp R, Geyer MA (2009). The 5-choice continuous performance test: evidence for a translational test of vigilance for mice. PLoS ONE 4: e4227.

Zarate CA, Singh JB, Carlson PJ, Brutsche NE, Ameli R, Luckenbaugh DA et al (2006). A randomized trial of an $N$-methyl-D-aspartate antagonist in treatment-resistant major depression. Arch Gen Psychiatry 63: 856-864.

Supplementary Information accompanies the paper on the Neuropsychopharmacology website (http://www.nature.com/npp) 